\title{
Claude Duchet, Patrick Maurus, Un cheminement vagabond. Nouveaux entretiens sur la sociocritique
}

\section{Pierangela Adinolfi}

\section{Q OpenEdition}

1 Journals

\section{Edizione digitale}

URL: http://journals.openedition.org/studifrancesi/3917

DOI: 10.4000/studifrancesi.3917

ISSN: 2421-5856

\section{Editore}

Rosenberg \& Sellier

\section{Edizione cartacea}

Data di pubblicazione: 1 décembre 2012

Paginazione: 626

ISSN: 0039-2944

\section{Notizia bibliografica digitale}

Pierangela Adinolfi, «Claude Duchet, Patrick Maurus, Un cheminement vagabond. Nouveaux entretiens sur la sociocritique», Studi Francesi [Online], 168 (LVI | III) | 2012, online dal 30 novembre 2015, consultato il 05 mars 2021. URL: http://journals.openedition.org/studifrancesi/3917 ; DOI: https:// doi.org/10.4000/studifrancesi.3917

Questo documento è stato generato automaticamente il 5 mars 2021.

\section{(c) $(1) \ominus$}

Studi Francesi è distribuita con Licenza Creative Commons Attribuzione - Non commerciale - Non opere derivate 4.0 Internazionale. 


\title{
Claude Duchet, Patrick Maurus, Un cheminement vagabond. Nouveaux entretiens sur la sociocritique
}

\author{
Pierangela Adinolfi
}

\section{NOTIZIA}

CLAUDE DUCHET, PATRICK MAURUS, Un cheminement vagabond. Nouveaux entretiens sur la sociocritique, Paris, Honoré Champion, 2011, pp. 266.

1 Il volume riunisce tre serie d'interviste, condotte da Patrick MAURUS e Isabelle TOURNIER, a Claude DUCHET, creatore nel 1971 del neologismo «sociocritique». Le interviste riguardano gli anni 1995, 1999-2001 e 2005. Le tre serie sono intervallate da tre gruppi di articoli, talvolta inediti, di Claude Duchet, che ricoprono l'arco temporale dal 1969 al 2005. Seguono la bibliografia, redatta da Kim IN-KYOUNG, dei lavori compiuti da Duchet dal 1962 al 2003 e un utile indice tematico.

2 La sociocritique in quanto lettura socio-storica del testo si costituisce gradatamente negli anni subito precedenti ed immediatamente successivi al 1968, nel tentativo di costruire una poetica della socialità, inseparabile dalla lettura del fatto ideologico nella specificità testuale. L'esplorazione sociocritica in Francia, caratterizzata da un andamento turbolento ed aleatorio, testimoniato anche dalla struttura del presente volume, ha le sue radici nel campo teorico degli anni Sessanta ed è oggi imbrigliata tra il formalismo post-strutturalista e la sociologia della letteratura ispirata da Bourdieu. Gli studi sociocritici condotti in Belgio, Svizzera e Québec dimostrano, al contrario, una vera e propria dinamica intellettuale ed accademica.

Per uscire dall'impasse, secondo Duchet il cheminement vagabond della sociocritique deve «ouvrir l'œuvre du dedans», a partire dalle pieghe più insospettate o strane del testo letterario, per far emergere la funzione della socialità. L'analisi teorica qui proposta, legata alla storia della letteratura del xIX secolo e soprattutto al genere romanzesco 
(Flaubert e Zola), si fonda sulle nozioni-chiave di «sociotexte» e «sociogramme». I sociogrammi come «Bourgeois», «Ville», «Dix-neuvième siècle», «Peuple», conferiscono una sorta di conflittualità alla «socialité romanesque». Il lavoro dello scrittore consiste, pertanto, nello sfumare, se non addirittura nel cancellare questa forza conflittuale, dando vita a ciò che Duchet chiama letteratura. La rifondazione della sociocritica, che si è definita anche rispetto ad altri approcci critici quali lo strutturalismo, il formalismo, la psicocritica, la psicanalisi, la sociologia e la narratologia, si rende oggi indispensabile, nella prospettiva di Duchet, per salvare la letteratura e per restituirla pienamente al mondo reale. 